\title{
Nova energetska kultura Sida hermaphrodita u Republici Hrvatskoj
}

\begin{abstract}
Sažetak
Sida hermaphrodita (Virginia fanpetals, Virginia Mellow) pripada porodici sljezovki (Malvaceae) porijeklom iz SAD-a i Kanade. To je ne prehrambeni, celulozni usjev, s brzim rastom i jako razvijenim korijenovim sustavom. Zahvaljujući njenom biokemijskom sastavu (sličnom lucerni), Sida se u zelenoj fazi, može koristiti $i$ kao visoko nutritivna hrana, sa sadržajem proteina i do $30 \%$ u vrijeme cvatnje. Sida omogućava $i$ proizvodnju do $120 \mathrm{~kg} / \mathrm{ha}$ kasnog prinosa meda. Ova jedinstvena vrsta, kada se žanje u suhoj fazi primjenjuje se kao energetska kultura, te se koristi za izolacije i te u celulozno-papirnoj industriji. U zelenom fazi koristi se u različitim industrijama i to farmaceutskoj industriji, industriji stočne hrane, industriji meda te u bioplinskoj industriji. Kao posebno profitabilna vrsta energetske kulture, sirovine budućnosti, već je predodređena da se koristi u industriji biogoriva. Plantaže Side imaju životni vijek najmanje 15-20 godina. Sida dobro raste u mnogim uvjetima na terenu i ne zahtijeva nikakve posebne uvijete tla.

Ključne riječi: Sida hermaphrodita, energetska kultura, biogorivo
\end{abstract}

\section{Uvod}

Zaštita okoliša napreduje, a samim time i razvoj proizvodnje energije i biogoriva. U posljednjih nekoliko godina za proizvodnju biogoriva dopušten je uzgoj neprehrambenih, višegodišnjih vrsta koje se koriste kao biomasa iz koje se proizvodi gorivo druge generacije (Simmons i sur., 2008). Neki poznati namjenski energetski usjevi koji ispunjavaju te kriterije su; vrba (Salix ssp.) (McCracken i sur., 2001; Ericsson i sur., 2006), topola i hibridne topole (Populus x ssp.) (Bunn $i$ sur., 2004). Manje poznate višegodišnje poljoprivredne kulture koje također zadovoljavaju kriterije su Miscantus x giganteus, Switch grass (Panicum virgatum L.), Sida hermaphrodita L. Rusby i mnogi drugi. Izgaranje fosilnih goriva ne samo da je dovelo do njihovog neizbježnog osiromašenja, već je također dovelo do velike količine zagađenja, uključujući stakleničke plinove u biosferi (Kitou i sur., 2007). Učinke izgaranja primjećuju se najviše u obliku klimatskih poremećaja. Smanjenje emisija stakleničkih plinova može se ostvariti kroz najnovije tehnologije, uštedu energije, povećanje učinkovitosti proizvodnje energije, koji osiguravaju zatvoreni sustav s obzirom na cirkulaciju i upijanje, osobito ugljika. Takvi obnovljivi izvori opskrbe energijom uključuju i orezanu biomasu iz nasada energetskih usjeva (Berndes i sur., 2003). Kako bi povećali granicu emisije ugljičnog dioksida, obzirom da je baš on prepoznat kao glavni izvor efekta staklenika, Europska komisija u 2014. godini proširuje Energetsku strategiju za Europu do 2020. godine (2009/28/EC) te navodi ciljeve i scenarije do 2030. godine, propisivanjem Okvira za klimatske i energetske politike.

Navedenim Okvirom predlaže se smanjenje emisija stakleničkih plinova za 40\%, povećanje udjela obnovljivih izvora energije od najmanje $27 \%$, kontinuirano poboljšavanje energetske učinkovitosti, te osiguranje konkurentne, pristupačne i sigurne energije. Biomasa kao izvor energije primjenjuju se za grijanje/hlađenje, proizvodnju električne energije, bioplina i drugu generaciju goriva. Da bi se ispunila velika potražnja biomase te izb-

Prof.dr.sc. Tajana Krička, Mateja Grubor, mag.ing.agr., Doc.dr.sc. Vanja Jurišić, Prof.dr.sc. Josip Leto, Izv. prof. dr. sc. Neven Voća, Doc.dr.sc. Nikola Bilandžija, Doc. dr. sc. Ana Matin Sveučilište u Zagrebu, Agronomski fakultet, Svetošimunska cesta 25, Zagreb, Hrvatska, e-mail: mgrubor @agr.hr 
jeglo korištenje tala pogodnih za proizvodnju hrane, budući se uzgoj energetskih nasada mora osloniti na marginalna i siromašna tla. Jedan od takvih energetskih nasada koje uspijevaju na nepovoljnim tlima je i nasad Side hermaphrodite, koji omogućuju proizvodnju biogoriva na temelju svog lignoceluloznog sastava, a životni vijek i vrijeme eksploatacije im je i do 20 godina. Osim kao energetski nasad, zbog svog kemijskog sastava i sličnošću s lucernom, poznata je i kao hrana za životinje te medonosna biljka. Sida hermaphrodita (L.) Rusby, eng. "Virginia fanpetals" ili „Virginia mallow" spada u skupinu sljezova (Malvaceae) (Spooner i sur., 1985) i potječe iz jugoistočnih područja Sjeverne Amerike (Kasprzyk i sur., 2014). U Europu je introducirana u 20-om stoljeću na područja Ukrajine i Poljske (Kasprzyk i sur., 2013). Izvorno je biljka relativno pjeskovitih tala s niskim udjelom organske tvari (Thomas, 1979).

\section{Rezultati i rasprava}

\section{Sistematika Side}

Sida je svrstana u grupu sljezovki (Malvaceae), znanstveni naziv joj je Sida hermaphrodita (L.) , a poznata je i po imenima Virginia fanpetals te Virginia Mallow (tablica 1.) Iltis (1963) je detaljno istražio razloge različitih generičkih tretmana koje je vrsta primila. Ova vrsta je dovoljno prepoznatljiva unutar roda te samim time Sida eventualno zaslužuju vlastiti rod (Fryxell, 1997). Sida hermaphrodita je zadržana u rodu prvenstveno zato što nije pronađen drugi srodni rod u koji bi se svrstala (Fuertes i sur., 2003).

Tablica 1. Sistematika Side hermaphrodite

\begin{tabular}{ll}
\hline Pozicija & Znanstveno ime i uobičajeno ime \\
\hline Domena & Plantea- Bilje \\
Carstvo & Tracheobionta- Vaskularne biljke \\
Koljeno & Spermatophyta- Sjemenjača \\
Potkoljeno & Magnoliophyta- Cvjetače \\
Razred & Magnoliopsida- Dvosupnice \\
Podrazred & Dilleniidea \\
Red & Malvales \\
Porodica & Malvaceae- Sljezovke \\
Rod & Sida L. \\
Vrsta & Sidahermaphrodita (L.) Rusby-Virginia fanpetals, Virginia Mallow \\
\hline
\end{tabular}

\section{Morfologija}

Sida hermaphrodita je višegodišnja kultura koja ima prosječnu visinu od $1-4,5$ metra (obično oko 3). Listovi su dugi i šiljasti, nalik javorovima te rastu naizmjenično uzduž stabljike. Obično sadrže 3 - 7 nepravilno nazubljenih režnjeva gdje je srednji najduži. Stabljika je obrasla dlačicama u mladom stadiju, dok sa zrelosti postupno izgrađuje glatku površinu. Cvat se formira od mnogo bijelih cvjetova te je cvatnja karakteristična za razdoblje od kolovoza do listopada, ali i do pojave prvog mraza. Svaki cvijet sadrži 5 latica duljine 8 milimetara (Kasprzyk i sur., 2013). Mladice izbijaju iz tla krajem travnja i početkom svibnja iz brojnih bočnih rizoma biljke, te im je životni vijek od 15 do 20 godina (Kasprzyk i sur., 2013). U prvoj godini vjerojatna je pojava jednog izdanka, dok se u četvrtoj i daljnjim godinama očekuje 20 - 30 izdanaka, što rezultira gustim sklopom (Biopaliwa, 2003). Takvom vegetativnom reprodukcijom nastaje eventualno klonalna populacija nekog područja zbog boljih uvjeta za rast. Klijavost biljke je poprilično niska 5-10\% (Antonowicz, 2005) 
te je vjerojatnost za genetsku raznolikost svedena na nižu razinu naspram uobičajenih razmjera (Franzaring i sur., 2013). Pomoću odgovarajućih metoda hidro-priprema moguće je klijavost povećati za više od 50\% (Grzesik i sur., 2011).

\section{Biologija}

Sida hermaphrodita je klonska višegodišnja biljka koja se širi rizomima ili sjemenom. Velike biljke mogu proizvesti nekoliko tisuća sjemenki, od kojih su većina održive (Spooner $i$ sur., 1985). Kod uzgoja, biljke mogu cvjetati i razmnožavati se već u prvoj godini (Spooner $i$ sur., 1985). Sjeme se sije kroz zimu, a klije u rano proljeće. Cvatnja počinje rano u kolovozu i nastavlja dok se ne dogodi teški mraz. Moguća metoda raspršivanja sjemena je i vodom. Ova vrsta biljka je otvorenih, vlažnih, sunčanih sa djelomičnim hladom priobalnih staništa (Spooner i sur., 1985). Tla na kojima Virginia Mallow prirodno uspijeva su relativno pjeskovita s prilično niskim sadržajem organske tvari, pH je neutralan do blago kiseo, a u takvim tlima su obično topljive soli dostupne biljkama (Thomas, 1979). Kultura je tolerantna na ekstremne tipove kontinentalne klime, posebno na zimske uvjete te na sušne uvjete ukoliko je godišnja razina padalina minimalno 400 - 500 milimetara (Borkowska i Molas, 2011). Spooner i sur. (1985) navode kako nije ograničena na određeni tip tla. Tla degradirana otpadnom vodom nisu ograničavajući čimbenik jer zbog svoje sposobnosti akumulacije određenih metala bez poteškoća raste na takvim onečišćenim tlima (Borkowska i Wardzinska, 2003). Posebne kompetencije s korovima nema jer se klijanje odvija u ožujku dok je tlo vlažno i hladno (Kurucz i sur., 2014). Točno vrijeme generacije je nepoznato, ali kultivirane biljke mogu živjeti 15 do 20 godina (Krzaczek i sur., 2006; Antonowicz 2005). Prva godina tijekom formiranja nasada daje vrlo niske prinos biomase, što je tipično za trajne nasade (Borkowska i Molas, 2013). Razmnožavanjem preko sjemena u prvoj godini dobiva se jedna stabljika dok se tijekom idućih godina razvije od nekoliko do preko 20 stabljika (Borowska i sur., 2009). Najveći prinosi primijećeni su u 3 i 4 godini uzgoja (Borowska i Styk, 2006; Borowska $i$ sur., 2006; Borowska $i$ sur., 2009). Sida hermaphrodita često je svrstana u vrste biljaka koje imaju visoki potencijal orezivanja (Szyszlak-Bargłowicz, 2014). Stabljika može doseći visinu do $4 \mathrm{~m}$ i širinu do $30 \mathrm{~mm}$ (Krzaczek i sur., 2006; Oleszek i sur., 2013). Biljku karakterizira čvrsto razvijen korjenov sustav. Velika prednost je mali zahtjevi za kvalitetom tla pa može biti uzgajana na tlima niže klase koja nisu korisna u poljoprivredne svrhe (Borkowska i Styk, 2003; Oleszek i sur., 2013).

\section{Zahtjevi tla}

Sida se zbog svojih niskih zahtjeva tla, koje su znatno niži od zahtjeva većine energetskih kultura, može koristiti za razvoj slabijih tala, uključujući sve vrste tla razreda $V$ pa sve do pjeskovitih tla. Ovo svojstvo Side je posebno značajno u slučaju njene upotrebe za rekultivaciju degradiranih i onečišćenih tala (Pszczolkowska $i$ sur., 2012). Potrebe gnojidbe od strane Side vrlo niske u godini osnivanja plantaža. Počevši od druge godine, preporučuje se doza N-P-K po hektaru od $90 \mathrm{~kg} \mathrm{~N}, 30-90 \mathrm{~kg} \mathrm{P}_{2} \mathrm{O}_{5}$ i 80-150 kg K $\mathrm{O}_{2}$. Istraživanja su pokazala da povećanje količine dušika od $200 \mathrm{~kg} / \mathrm{ha}$ nema utjecaj na broj izbojaka. Međutim, povećanjem gnojidbe fosforom od 39 do $53 \mathrm{~kg} / \mathrm{ha}$ povećava se broj izbojaka i to prosječno jedan izbojak po četvornom metru, što daje ukupno oko 20.000 dodatnih izdanaka po hektaru (Borkowska $i$ sur., 2009). Nadalje, istraživanja su pokazala da korištenje obrađenog kanalizacijskog mulja povećava prinos biomase i olakšava njezin uzgoj i na vrlo siromašnim tlima (Romanowska-Duda i sur., 2009; Kacprzak i sur., 2010). 


\section{Sadnja i žetva}

Sida se reproducira i kroz presadnice posađene u gustoći 10 000-20 000 po hektaru (Pszczolkowska i sur., 2012). Nasade višegodišnjih vrsta, uključujući i Sidu, karakterizira presušivanje mladica na kraju vegetacije. Dakle, razina vlage značajno ovisi o datumu žetve. Sida do kraja vegetacijskog razdoblja odbacuje svo lišće i samo ostaje stabljika (Borkowska i Molas, 2013). Žetva biomase, ovisno o regiji, provodi se u mjesecima veljači, ožujku i travnju ili u vrijeme prvih mrazeva u studenom i prosincu. Sadržaj vlage biomase u prirodnim uvjetima smanjuje se od oko $40 \%$ u studenom na oko $20 \%$ u siječnju (Borkowska i Styk 2006). Žetva biomase sa sadržajem vlage $20 \%-24 \%$ iznosi $20-25$ tona po ha (Denisiuk, 2006). U slučaju žetve Side, samo male količine sastojaka gnojiva su odstranjene iz polja, jer kako se mladice suše, hranjive tvari nalaze se u rizomu ili se vraćaju u tlo kroz pad lišća. Biomasa Side prikupljena u pravo vrijeme karakterizira nizak sadržaj pepela i relativno malo mineralnih sastojaka kao što su dušik, kalij i klor (Pszczolkowska i sur., 2012).

\section{Bolesti i štetnici}

Za Sidu se govorilo da je biljka bez prirodnih neprijatelja (Borkowska i Styk, 2006). Međutim, prema Zavodu za zaštitu bilja iz Poznana, Poljska (IOR), oko 30\% biljaka na plantaži mogu biti zaražene crvenim paukom i lisnim ušima. Imajući u vidu veličinu Side, njihova štetnost je mala i ne zahtijeva primjenu skupih i ekološki nepoželjnih zaštitnih operacija. Sida može biti također zaražena s brojnim svejedima polukrilca poput smeđe stjenice (Coreus marginatus L.) i različite lygus stjenice (Lygus spp). Sve veća količina tih insekata sugerira da u slučaju višegodišnjih nasada oni, kao i gusjenice leptira, mogu biti prijetnja (Mrowczynski i sur., 2007;. Remlein-Starosta i Nijak, 2007). Sida je također osjetljiva na gljivične infekcije Fusarium, Sclerotinia sclerotiorum i Botritis tipa cinerea, uzrokujući fuzarioze, Sclerotinia sclerotiorum plijesni i plemenite plijesni (Grzesik i sur., 2011).

\section{Upotreba}

U početku, Sida je korištena kao vlaknasta, stočna hrana i medonosna biljka, a tek nedavno je postala popularna kao energetski usjev. U ranoj fazi rasta (prije cvjetnih pupova), nadzemni dio stabljike je tamno zelene boje, a sadrži visoku razinu dragocjenih sastojaka te se može usporediti s visokokvalitetnom krmom- lucernom (Tablica 2). Na površini biomase Sida sadrže proteine, aminokiseline, vitamin C, karoten i druge važne elemente (slično lucerni) kao što je navedeno kao povoljne kvalitete za stočnu hranu. Dalje, na početku cvatnje, celuloza i lignin će biti dominantni, a na kraju vegetacijske sezone, utvrđeno je više od 50\% celuloze u suhoj tvari stabljike (Borkowska i sur., 2009; Borkowska i Molas, 2011).

Tablica 2. Sadržaj osnovnih probavljivih sirovih hranjivih tvari u suhoj tvari Side i lucerne (\%)

\begin{tabular}{llllll}
\hline Fenološka faza & Proteini & Masti & Vlakna & DNFE* & Pepeo \\
\hline Sida & & & & & \\
Stvaranje cvjetnih pupova & 20,00 & 1,82 & 28,75 & 38,11 & 11,31 \\
Kraj cvatnje & 7,52 & 1,42 & 51,54 & 34,91 & 4,6 \\
Lucerna & & & & & \\
Stvaranje cvjetnih pupova & 23,23 & 3,59 & 24,98 & 35,95 & 12,25 \\
Kraj cvatnje & 16,64 & 3,59 & 37,20 & 30,09 & 9,02 \\
\hline
\end{tabular}

*DNFE-Digestible Nitrogen-Free Extract-Probavljivi ekstrakt bez dušika Izvor: Borkowska i Styk, 2006; Borkowska i Molas, 2011 
Često se koristi u Sjevernoj Americi, a također se uzgaja i koristi u Poljskoj i Rusiji za različite namjene. Najvažnija primjena Side u tim zemljama je primjena kao biomase za stvaranje biogoriva iz obnovljivih izvora energije (Borkowska, 2007). Druga identificirana upotreba ove biljke je u industriji papira i celuloze, jer sadržaj celuloze, smole i voska koji proizlazi od ove biljka je usporediva s onom koja se nalazi u smreki i boru (Borkowska i Styk, 2006). Sida preživi do pojave prvog mraza i stoga je korisna i u pčelarstvu kao izvor kasnog nektara. Tijekom cvatnje Sida hermaphrodita može proizvesti 110 do $315 \mathrm{~kg} /$ ha (Pszczolkowska i sur., 2012) te do 120 kg/ha kasnog prinosa meda (Wroblewska i Kolasa, 1986; Borkowska i Styk, 2006). Sida također sadrži tvari slične medicinskom gavezu i mogu se koristiti u farmaceutskoj industriji. Sida se koristi za sadnju na kemijski degradiranim terena i deponijima, a također se može uzgajati za zaštitu na erozivnim obroncima (Borkowska i Styk 2006). Predmet je interesa mnogih istraživača s obzirom na činjenicu da je brzo rastuća biljka s visokim potencijalom prinosa i mogućnošću višestrukog ponovnog rasta nakon rezanja. Vrlo je prilagodljiva različitim klimatskim uvjetima i uvjetima tla. Može se uzgajati na padinama, erodiranim područjima, zemljištima koja su isključena iz poljoprivredne upotrebe, na kemijski onečišćenim područjima, i na odlagališta smeća (Kasprzyk i sur., 2014). Ovisno o gustoći biljaka, prinos biomase je u rasponu između 10-20 t/ha (Borkwska i Wardzinska, 2003; Borkowska, 2007), dok je kalorična vrijednost biljke oko 15-17 $\mathrm{MJ} / \mathrm{kg}$ suhe tvari (Kus i Matyka, 2010; Oleszek i sur., 2013). Vrlo vrijedna osobina ove vrste je velika količina suhe tvari u stabljici neposredno nakon berbe, te se stoga može koristiti kao potencijalni materijal za proizvodnju zelene energije (Szyszlak i sur., 2006.; Oleszek $i$ sur., 2013).

\section{Zaključak}

Sida hermaphrodita je kultura koja ima široku upotrebu, dobre hranidbene i energetske karakteristike te niskih zahtjeva vezano za tlo. Hranidbena vrijednost slična je lucerni, a ogrjevna vrijednost joj je oko $17 \mathrm{MJ} / \mathrm{kg}$ suhe tvari. Pravilnom pripremom sadnica postiže se kvalitetan i visok prinos. Puni nasad postiže treće i četvrte godine, a životni vijek je i do 20 godina. Prilagodljiva je svim tlima, a prilikom žetve iz njih ne iscrpljuje minerale pa je samim time dobra i za njihovu regeneraciju.

\section{Zahvala}

Ovo istraživanje financiralo je Ministarstva poljoprivrede u okviru VIP projekta „Potencijal energetske kulture Sida hermaphrodita na ekološkom poljoprivrednom gospodarstvu".

\section{Literatura}

Antonowicz J. (2005). Potencjał energetyczny ślazowca pensylwańskiego (Energy potential of the Virginia mallow), "AURA", 3, 7-9.

Berndes G, Hoogwijk M, Broek R. (2003). The contribution of biomass in the future global energy supply: a review of 17 studies. Biomass Bioenergy, 25,1-28.

Biopaliwa (2003). Collective work, edited by Piotr Gradziuk, edition by Wieś Jutra, 68.

Borkowska H. (2007). Yields of Virginia fanpetals and willow on good wheat soil complex. Fragmenta Agronomica, $2,41-47$.

Borkowska H., Molas R. (2011). Two extremely different crops, Salix and Sida, as sources of renewable bioenergy. Biomass and Bioenergy, 46, 234-240.

Borkowska H., Molas R. (2013). Yield comparison of four lignocellulosic perennial energy crop species. Biomass and Bioenergy, 51, 145-153.

Borkowska H., Molas R., Kupczyk, A. (2009). Virginia Fanpetals (Sida hermaphrodita Rusby) Cultivated on Light Soil;Height of Yield and Biomass Productivity, Polish J. of Environ. Stud, 18(4), 563-568,

Borkowska H., Styk B. (2006). Virginia fanpetals (Sida hermaphrodita Rusby) - cultivation and use. WAR, Lublin, 69.

Borkowska H., Styk B., Molas R. (2006). Energy cultivation of high potential. Erneuerbare Energien, 7, 76.

Borkowska H., Wardzinska K. (2003). Some effects of Sida hermaphrodita R. cultivation on sewage sludge. Polish Journal of Environmental Studies, 12(1), 119-122.

Borkowska, H., Styk, B. (2003). Virginia mallow. In Borkowska, H., Dubas, J.W., Gradziuk, P., Kooecik, B., Kooecik, K., KowalczykJuoeko, A., Martyn, W., Sawicki, B., Styk, B. and Wêgorek, T. (eds). Energy Crops (in Polish). Agriculture Academy Publishing, Lublin, pp. 79- 93 .

Bunn SM, Rae AM, Herbert CS, Taylor G. (2004). Leaf-level productivity traits in Populus grown in short rotation coppice for 
biomass energy. Forestry 77(4), 307-323.

DenisiukW. (2006). Produkcja roślinna jako źródło surowców energetycznych (Plant production as a source of energy raw materials), Inżynieria Rolnicza (Agricultural Engineering), 5, 123-131.

Ericsson K, Rosenquist H, Gank E, Pisarek M, Nilsson L. (2006). An agro-economic analysis of willow cultivation in Poland. Biomass Bioenergy, 30, 16-27.

Franzaring J., Holz I., Kauf Z., Fangmeier A. (2015). Responses of the novel bioenergy plant species Sida hermaphrodita (L.) Rusby and Silphium perfoliatum L. to CO 2 fertilization at different temperatures and water supply. Biomass and Bioenergy, 81 , 574-583.

Fryxell, P. A. (1997). The American genera of Malvaceae-Il, Brittonia, 49(2), 204-269.

Fuertes, J., P. A. Fryxell, Jansen, R. K (2003). Phylogenetic relationships andclassification of the Sida generic alliance (Malvaceae) based on nrDNA ITS evidence, Systematic Botany, 28(2), 352-364.

Grzesik M., Janas R., and Romanowska-Duda Z. B. (2011). Stymulacja wzrostu i procesów metabolicznych ślazowca pensylwańskiego (Sida hermaphrodita) (Stimulating the growth and metabolic processes of the Virginia mallow (Sida hermaphrodita)), "Problemy Inżynierii Rolniczej (Problems in Agricultural Engineering)", 4, 81-87.

Iltis, H.H. (1963). Napaea dioica (Malvaceae): whence came the type?. American Midland, Naturalist, 70, 90-109.

Kacprzak M., Ociepa A., Bien J. (2010). The influence of Soil Fertilization on the Amounts of Ashes and Contents of Heavy Metals in Biomass Ashes. "Archivum Combustionis", 30(3), 126-131.

Kasprzyk A. , Leszczuk A., Szczuka E. (2014). Virginia mallow (Sida hermaphrodita (I.) rusby) - properties and application, Modern Phytomorphology 6, 91 .

Kasprzyk A., Leszczuk A., Domaciuk M., Szczuka E. (2013). Stem morphology of the Sida hermaphrodita (L.) Rusby (Malvaceae). Modern Phytomorphology, 4, 25.

Kitou E, Barkman A, Fernandez R, Gugele B, Kampel E, Mareckova K. (2007). Annual European Community greenhouse gas inventory 1990e2005 and inventory report 2007. Brussels: EEA, European Commission, DG Environment; p. 464.

Krzaczek, P., Szyszlak, J., Zarajczyk, J. (2006). Assessment of the influence of selected operating parameters of S071/B KRUK seeder on seeding Sida hermaphrodita Rusby seeds. Int. Agrophys., 20, 297- 300.

Kurucz, E., Antal, G., Gábor, F. M., Popp, J. (2014). Cost-effective mass propagation of Virginia fanpetals (Sida hermaphrodita (L.) Rusby) from seeds. Environmental Engineering \& Management Journal (EEMJ), 13(11), 2845-2852. $1-64$.

Kuś, J., Matyka, M. (2010). Plant Cultivation for Energy Purposes. Dissemination Instruction. IUNG Pulawy Publisher, 176,

McCracken A.R., Dawson W.M., Bowden G. (2001). Yield responses of willow (Salix) grown in mixtures in short rotation coppice (SRC). Biomass Bioenergy, 21(5), 311-319.

Mrówczyński M., Nijak K., Pruszyński G., Wachowiak H. (2007). Zagrożenie roślin energetycznych przez szkodniki" (Pest threats to energy plants). Postępy w ochronie roślin (Progress in Plant Protection), 47(4), 347-350.

Oleszek, M., Matyka, M., Lalak, J., Tys, J., Paprota, E. (2013). Characterization of Sida hermaphrodita as a feedstock for anaerobic digestion process. Journal of Food, Agriculture \& Environment, 11(3-4), 1839-1841.

Pszczółkowska A., Romanowska-Duda Z., Pszczółkowski W., Grzesik M., Wysokińska Z, (2012). Biomass Production of Selected Energy Plants: Économic Analysis and Logistic Strategies, Comparative Economic Research, 3(15), 77-103.

Remlein-Starosta D., Nijak K. (2007). Ślazowiec pensylwański - wstępne wyniki badań nad możliwościami ochrony przed agrofagami (The Virginia mallow: Preliminary results of research on the potential for protection against agrophages), Postępy $w$ Ochronie Roślin (Progress in Plant Protection), 47(4), 358-362.

Romanowska-Duda Z. B., Grzesik M., Piotrowski K. (2009). Ecological Utilization of Sewage Sludge in Production of Virginia Fanpetals (Sida hermaphrodita Rusby): Biomass as the Source of Renewable Energy. U: Proceedings of the 2nd International Conference on Environmental Management, Engineering, Planning and Economics (CEMEPE) and SECOTOX Conference, Mykonos, edited by A. Kungolos, K. Aravossis, A. Karagiannidis, and P. Samaras, GRAFIMA Publishers, D. Gounari, 62-68, Thessaloniki, vol. III, p. 1261-1266. 242. Simmons B.A., Loque D, Blanch H.W. (2008). Next-generation biomass feedstocks for biofuel production. Genome Biol, 9 ,

Spooner D. M., Cusick A. W., Hall G. F., Baskin J.M. (1985). Observations on the distribution and ecology of Sida hermaphrodita (L.) Rusby (Malvaceae). SIDA, 11 (2), 215-225.

Szyszlak, J., Piekarski, W., Krzaczek, P., Borkowska, H. (2006). Analysis of possible utilization of Virginia mallow for energy purposes. Inżynieria Rolnicza, 6(81), 311-318.

Szyszlak-Bargłowicz, J. (2014). Content of chosen macroelements in biomass of Virginia mallow (Sida hermaphrodita Rus-

by). Journal of Central European Agriculture, 15(3), 263-271

Thomas L.K. (1979). Distribution and ecology of Sida hermaphrodita: a rare plant species. Bartonia, 46, 51-59.

Wroblewska A., Kolasa, Z. (1986). Bee's yield from Sida. Beekeeping Magazine,10, 6.

\section{Sida hermaphrodita as novel energy crop in Republic of Croatia}

\section{Abstract}

Sida Hermaphrodita (Virginia fanpetals, Virginia Mallow) belongs to the Mallow (Malvaceae) family, is a species native to the USA and Canada. It is a non-food, cellulosic crop, with fast growth and strongly developed root system. Thanks of its bio-chemical composition (similar to alfalfa), Sida, in the green stage, can be used as a highly nutritious feed, with a protein content up to $30 \%$ During the flowering time, Sida allows to be produced up to $120 \mathrm{~kg} / \mathrm{h}$ a of late yield honey. This unique species, by harvesting in the dry stage, has applications in the bioenergy, insulation and cellulose-paper industries. In the green stage its use is in the different industries, in pharmaceutical industry, fodder industry, honey industry, bio-gas industry. As a particularly profitable energy species, future feedstock, is already predestined to use it in bio-fuel industry. Sida plantations have a useful lifespan for at least 15-20 years. Sida grows well under many site conditions and does not have any special soil requirements.

Keywords: Sida hermaphrodita, energy crop, biofuel 